\title{
Mentha piperita Effects on Wistar Rats Plasma Lipids
}

\author{
Sandra Maria Barbalho ${ }^{1,2 *}$, Ana Paula Machado Spada ${ }^{2}$, Erick Prado de Oliveira ${ }^{2}$, Márcio \\ Emilio Paiva-Filho², Karla Aparecida Martuchi ${ }^{2}$, Náyra Coelho Leite ${ }^{2}$, Renata Maeda \\ Deus $^{2}$, Vivianne Sasaki ${ }^{2}$, Lucas Silva Braganti ${ }^{2}$ and Marie Oshiiwa ${ }^{1,2}$ \\ ${ }^{1}$ Departamento de Bioquímica; Escola de Medicina de Marilia; Marilia - SP - Brasil. ${ }^{2}$ Departamento de Nutrição; \\ Universidade Metodista de Piracicaba; Lins - SP - Brasil
}

\begin{abstract}
The aim of this study was to demonstrate the effects of Mentha piperita juice and tea on plasma lipids of Wistar rats. The animals were divided in control group (CG) and four treated groups: TG1 treated with tea and TG2 treated with juice (both receiving commercial rat chow); TG3 and TG4 were fed with supplemented fat chow (with hydrogenated fat and soybean oil) and treated respectively with tea and juice. Both tea and juice were administered by intra-gastric route (gavage) two times a day for 30 days. TG2 and TG4 animals showed significant decrease in triacylglycerols and increase in HDL-c levels. TG1 and TG2 also showed lower cholesterol values. The levels of LDL-c increased in CG but decreased in the treated groups. Animals of TG1, TG2 and TG4 showed substantial reduction in food intake and in percentage of weight gain. TG3 increased food intake but did not increase the percentage of weight gain.
\end{abstract}

Key words: Mentha piperita, cholesterol, HDL-c, LDL-c, triacylglycerol

\section{INTRODUCTION}

Around the world, a wide variety of plants are commonly used as remedies for the treatment of many diseases. The use of these plants to control blood sugar and lipid levels in plasma is widespread and many studies have shown that some plants do have beneficial effects (Song and Lee, 2003; Zou et al., 2005).

Hypercholesterolemia and low HDL-c (high density lipoprotein-cholesterol) levels are very common today and are often associated with endothelium dysfunction and inflammation, which are often followed by atherosclerosis. High levels of total cholesterol, LDL-c (low density lipoprotein cholesterol) and triacylglycerol associated with lower HDL-c levels can also induce insulin resistance and higher risks of cardiovascular diseases (Willa and Quinones, 2003; Yki-Järvinen, 2003). The combination of all these factors can trigger the Metabolic Syndrome (Lorenzo et al., 2006; Gogia and Agarwal, 2006). Endothelial dysfunction and cardiovascular diseases can be prevented by controlling plasma lipids (Vakkilainen et al., 2000).

The lack of information about the possible toxic effects of many plants, allied to the high cost of allopathic medicines, encourages the use of the former in the treatment of many diseases. This indicates the pressing need for new studies to

*Author for correspondence: smbarbalho@terra.com.br 
clarify the real effects of medicinal plants and to provide scientific evidence establishing their usefulness.

Mentha piperita (Family Labiatae; genus Mentha) is one of the ten most widely used plants in Brazil (Cortez et al., 1999) and is commonly used in the treatment of loss of appetite, common cold, bronchitis, fever, nausea, vomiting (Akdogan et al., 2003), spasmodic responses (Lu et al., 2002), and antimicrobial and antioxidant activities (Romero-Jimenez et al., 2005; Mimica-Dukic et al., 2005).

Due to the important role of high plasma lipids in the development of insulin resistance, atherogenesis and cardiovascular disease, and the widespread use of $M$. piperita as a complementary and alternative medicinal intervention, this study aimed to investigate the effects of tea and juice prepared with fresh peppermint leaves (which is how the population uses this plant) on Wistar rats plasma lipids.

\section{MATERIALS AND METHODS}

\section{Animals}

Twenty one days old male Wistar rats (220-250g) were used and were provided ad libitum with food and water; $22 \pm 2^{\circ} \mathrm{C} ; 12 \mathrm{~h}$ dark/light cycle and $60 \% \pm 5 \%$ in air humidity at the Piracicaba Methodist University - UNIMEP, São Paulo, Brazil. The animals were cared following the recommendations laid out by the Canadian Council's "Guide for the care and use of experimental animals" and they were divided into five groups $(\mathrm{n}=12)$ : control group (CG) and four treatment groups (TG). Throughout the experiment, all the groups received water ad libitum; the CG, TG1 and TG2 received commercial rat feed (Purina ${ }^{\circledR}$ LTDA, São Paulo Brazil) and TG3 and TG4 were fed with supplemented rat feed. This supplement was saturated fat and soybean oil.

In the first month of the experiment, all the groups received only water (time 1 ). In the second month (time 2), using the intragastric route (gavage), $\mathrm{CG}$ received water, TG1 and TG3 received $M$. piperita tea and TG2 and TG4 received $M$. piperita juice. All the groups were treated twice daily (mornings and afternoons) for 30 days. Water and food intake was analyzed daily and the body weight twice a week.

\section{Extract preparation and administration}

The $M$. piperita plant was obtained and identified by an expert from the Department of Pharmacology, Discipline of Homeopathy University of Marilia (UNIMAR).

The juice was prepared by mashing the leaves in water $(100 \mathrm{~g} / \mathrm{L})$ for 3 minutes and the tea was prepared by infusion of the leaves $(100 \mathrm{~g} / \mathrm{L})$ in water at $100^{\circ} \mathrm{C}$ for 10 minutes. The treatment groups received a dose of $0.29 \mathrm{~g} / \mathrm{kg}$ twice a day (analogous to the popular form of consumption of the plant: a person weighing $70 \mathrm{~kg}$ drinks $200 \mathrm{~mL}$ of peppermint tea or juice twice a day).

\section{Supplemented feed preparation}

The supplemented feed was prepared by grinding commercial rat feed and mixing it with soybean oil (1\%) and hydrogenated fat (9\%) (adapted from Camacho et al., 1996; Sabarense and Mancini, 2003). The food pellets were prepared and dried at $60^{\circ} \mathrm{C}$.

\section{Biochemical parameters}

At the end of time 1 and 2, blood was collected by tail puncture and the plasma was used to determine the total cholesterol, LDL-c and HDL-c, and triacylglycerols. These analyses were carried out using commercial kits (LABTEST $^{\circledR}$ for cholesterol, HDL-c and triacylglycerols and WIENER LAB ${ }^{\circledR}$ for LDL-c and the anticoagulant used was heparin).

\section{Statistics}

The comparison between the experimental groups was made by two-way analysis of variance (ANOVA) and Student's test (Standard Deviation). The probability of 5\% was considered to be statistically significant.

\section{RESULTS}

A comparison between time 1 and 2 of the experiment in each group (Table 1) showed that there was a significant increase in the values of triacylglycerol in CG, while the groups treated with peppermint tea (TG1 and TG3) showed a non-significant decrease. The groups treated with the juice (TG2 and TG4) showed a significant reduction in triacylglycerol values.

No reduction in total cholesterol (Table 1) was observed in all the groups in time 1 and time 2. 
Analyzing the time 1 and comparing with $\mathrm{CG}$, it was possible to say that only TG2 had higher triacylglycerol values and TG1 and TG2 had lower cholesterol values (Table 1).

Analyzing the time 2 and comparing with $\mathrm{CG}$, it was found that only TG2 had lower triacylglycerol values and TG1 and TG2 had lower cholesterol values (Table 1).

As shown in Table 2, the comparison between time 1 and time 2 in each group showed that LDL-c had significant increase only in CG. Considering only time 1 , any group had significant differences when compared to $\mathrm{CG}$, but when comparison was made in time 2, TG1 and TG2 had significant decrease.

Comparing the values of HDL-c in time 1 and time 2 in each group, it was seen (Table 2) that only TG2 had significant increase. In time 1, TG1 and TG2 presented significant lower values when compared to $\mathrm{CG}$. The comparison in time 2 showed that only TG2 had significant increase in HDL-c values.

Table 1 - Biochemical parameters values before (time 1) and after (time 2) treatment with M. piperita. Values in $\mathrm{mg} / \mathrm{dL}$.

\begin{tabular}{ccc}
\hline & triacylglycerols & cholesterol \\
\hline CG (time 1) & $51.90 \pm 17.33$ & $84.00 \pm 25.12$ \\
CG (time 2) & $97.83 \pm 7.16^{*}$ & $86.40 \pm 23.79$ \\
TG1 (time 1) & $68.12 \pm 38.71$ & $58.56 \pm 12.49^{* *}$ \\
TG1 (time 2) & $55.32 \pm 43.54$ & $53.62 \pm 14.97 * * *$ \\
TG2 (time 1) & $93.85 \pm 26.65 * *$ & $59.29 \pm 17.19^{* *}$ \\
TG2 (time 2) & $52.95 \pm 20.73 * / * * *$ & $49.22 \pm 16.98^{* * *}$ \\
TG3 (time 1) & $102.97 \pm 32.26$ & $73.89+21.87$ \\
TG3 (time 2) & $77.43 \pm 44.03$ & $68.42 \pm 20.73$ \\
TG4 (time 1) & $131.70 \pm 42.22$ & $66.77 \pm 23.55$ \\
TG4 (time 2) & $86.85 \pm 36.25^{*}$ & $70.50 \pm 42.87$ \\
\hline
\end{tabular}

*Values are significantly different in time 1 and $2(\propto=5 \%)$.

**Values are significantly different in time 1 when compared to the $\mathrm{CG}(\propto=5 \%)$.

***Values are significantly different in time 2 when compared to the $\mathrm{CG}(\propto=5 \%)$.

Table 2 - Biochemical parameters values before (time 1) and after (time 2) treatment with M. piperita. Values in $\mathrm{mg} / \mathrm{dL}$.

\begin{tabular}{ccc}
\hline & LDL-c & HDL-c \\
\hline CG (time 1) & $23.30 \pm 15.59$ & $50.34 \pm 6.42$ \\
CG (time 2) & $44.30 \pm 18.01^{*}$ & $22.53 \pm 18.67$ \\
TG1 (time 1) & $12.18 \pm 9.94$ & $32.77 \pm 11.54 * *$ \\
TG1 (time 2) & $7.66 \pm 1.85 * * *$ & $36.47 \pm 14.94$ \\
TG2 (time 1) & $14.42 \pm 18.91$ & $24.84 \pm 5.20 * *$ \\
TG2 (time 2) & $9.55 \pm 11.13 * * *$ & $46.35 \pm 19.42 * / * * *$ \\
TG3 (time 1) & $27.65+20.59$ & $25.64+5.29$ \\
TG3 (time 2) & $17.02 \pm 11.30$ & $36.53 \pm 15.31$ \\
TG4 (time 1) & $43.86 \pm 17.81$ & $28.03 \pm 7.74$ \\
TG4 (time 2) & $28.60 \pm 16.59$ & $59.30 \pm 41.82$ \\
\hline
\end{tabular}

*Values are significantly different in time 1 and $2(\propto=5 \%)$.

**Values are significantly different in time 1 when compared to the $\mathrm{CG}(\propto=5 \%)$.

$* * *$ Values are significantly different in time 2 when compared to the CG $(\propto=5 \%)$. 
Since TG3 and TG4 received different diets, the biochemical parameters, food intake and percentage of body weight gain were not compared to the CG. These groups were compared themselves only in time 1 and 2 and significant difference (decrease) was observed only in triacylglycerol levels in TG4 (Table 1).

In percentages, comparing time 1 and $2, \mathrm{CG}$ showed increase in triacylglycerols $(88.50 \%)$, cholesterol (2.86\%), LDL-c $(90.13 \%)$ and decrease in HDL-c $(55.24 \%)$. TG1 showed decrease in triacylglycerols $(18.79 \%)$, cholesterol $(8.44 \%)$, LDL-c $(37.11 \%)$ and increase HDL-c (11.29\%).

TG2 showed decrease in triacylglycerols (43.58\%), cholesterol (16.98\%), LDL-c (33.77\%) and increase in HDL-c (86.59\%). TG3, even with the fat diet, showed decrease in triacylglycerols (24.80\%), cholesterol (7.40\%), LDL-c (38.44\%), and increase of HDL-c (42.47\%). TG4 showed reduction in triacylglycerols $(34.05 \%)$ and LDL-c (34.79\%), slight increase in cholesterol (5.59\%), and increase in HDL-c (111.56\%).

Table 3 showed that CG and TG3 had significant increase in food intake when time 1 was compared with time 2. The opposite occurred to TG1, TG2 and TG4 (reduction of $37.12 \%, 36.15 \%$ and $51.37 \%$, respectively). TG1 and TG2 had significant decrease.

Table 4 showed that only CG did not have variation in body weight gain comparing time 1 and 2. The other groups presented reduction in the percentage of weight gain.

Table 3 - Food intake values before (time 1) and after (time 2) treatment with Mentha piperita. Values in g.

\begin{tabular}{ccc}
\hline & Time 1 & Time 2 \\
\hline CG & $114.72 \pm 33.36$ & $164.00 \pm 25.78^{*}$ \\
TG1 & $264.81 \pm 48.51^{* *}$ & $166.50 \pm 73.30^{*}$ \\
TG2 & $248.70 \pm 62.01^{* *}$ & $158.80 \pm 79.73^{*}$ \\
TG3 & $142.09 \pm 62.37$ & $205.80 \pm 74.90^{*}$ \\
TG4 & $304.76 \pm 44.36$ & $148.22 \pm 38.94 *$ \\
\hline
\end{tabular}

*Values are significantly different in time 1 and $2(\propto=5 \%)$.

**Values are significantly different in time 1 when compared to the $\mathrm{CG}(\propto=5 \%)$.

Table 4 - Variations for body weight gain during time 1 and time 2 . Values in $\%$.

\begin{tabular}{ccc}
\hline & Time 1 & Time 2 \\
\hline CG & $15.75 \pm 1.14$ & $12.68 \pm 3.98$ \\
TG1 & $15.84 \pm 4.28$ & $6.86 \pm 2.20^{*}$ \\
TG2 & $18.71 \pm 4.16$ & $10.02 \pm 3.87^{*}$ \\
TG3 & $11.89 \pm 2.66$ & $-0.10 \pm 3.39^{*}$ \\
TG4 & $13.03 \pm 4.93$ & $-0.55 \pm 2.30^{*}$ \\
\hline
\end{tabular}

*Values are significantly different in time 1 and $2(\propto=5 \%)$.

TG3 had significant decrease in percentage of weight gain even increasing the food consumption. TG4 reduced its ingestion and also its weight gain percentage.

In the beginning of the study all the animals had about 220-250g. The rats in CG, TG1 and TG2 had the same diet and were kept under same conditions (as well TG3 and TG4), hence no explanation can be found for the differences in food intake observed in CG, GT1 and GT2 or between GT3 and GT4.

\section{DISCUSSION}

As a result of globalization, the new trends of the world economy in the sector of nutrition have led to rapid changes in dietary patterns, as evidenced by the ever expanding consumption of fat-rich foods, which has contributed to the increase in lipids and growing body weight.

Dyslipidemias are important factors in the development of insulin resistance. Type 2 diabetes mellitus, atherosclerosis, heart disease and cerebral 
vascular accidents, and also constitute an independent risk of coronary artery disease (Manco et al., 2004).

Plants such as soybean (Song and Lee, 2003), eggplant (Camacho et al., 1996), green tea (Kuo et al., 2005) and others are widely cited in the literature as the targets of studies relating to hypocholesterolemic effects.

$M$. piperita is considered one of the ten plants most commonly used by the Brazilian population for therapeutic purposes. Thanks to its low cost, people cultivate this and other plant species in their gardens and consume them more frequentlyin the form of boiled tea for treating a wide variety of ills (Cortez et al., 1999).

This study demonstrated the efficacy of $M$. piperita in improving the lipid profile of animals. A remarkable fact is that this plant is normally consumed in the form of tea, but some beneficial effects (significant reduction of triacylglycerols and increase in HDL-c) has been achieved with the juice from the leaves.

The LDL-c levels of the CG were significantly higher in time 2 than in time 1. A comparison of CG's time 2 with that of the other groups revealed a significant decrease in LDL-c after treatment with juice and tea. Furthermore, the animals of TG3 and TG4, despite their supplemented fat diet, did not show an increase in LDL-c (Table 2). The HDL-c levels benefited significantly from the use of $M$. piperita juice, even when the animals received feed supplemented with saturated fats.

The $M$. piperita treatment led to a reduction in the weight gain percentage (Table 4), even in the presence of increased food consumption (TG3). The remaining groups showed a marked reduction in food intake. The available literature does not report on mechanisms to explain these findings. More detailed studies should be conducted to explain these results.

Many studies have been carried out to investigate the health benefits of Mentha species and many volatile components have been analyzed and isolated from this and other medicinal plants. The volatile extracts of $M$. arvensis contain menthol, muurolol, eugenol, thymol, ketones (methyl acetate and jasmonate) and hydrocarbons (dihydroactinidiolide, germacrene D and calamenene). In $M$. piperita leaves, menthol and myrcene have been identified as key volatile components. The phenolic components are responsible, at least in part, for the antioxidant and antiperoxidant effects (Ka et al., 2005; Edris et al., 2003).

In addition to its antioxidant and antiperoxidant effects, $M$. piperita extract has important radicalscavenging activity and this is associated with phenolic acids, flavonoids, terpenoids and other components. It is also suggested that alcoholic compounds such carveol may remain complexed with transition metals, contributing to the scavenging properties (Samarth et al., 2006). The biological chiral terpenes in this species have been reported by del Castillo et al., (2004).

Flavonoids may act in a number of different ways on the various components of the blood, such as lipids (Doyama et al., 2005). Literature data may not be sufficient to explain the effects on plasma lipids, but phenolic acids, flavonoids and terpenoids, besides their antioxidant effects, may also be associated with benefits for triacylglycerol and HDL-c, as found by Choudhury et al., (2006) in their study using Mentha spicata leaves.

The results obtained in this study could be important in terms of improvement of the lipid profile and to reduce food consumption and weighted gain. However the use of medicinal plants should be viewed with caution, since it often cannot substitute the medication needed to treat a patient's disease.

In view of the fact that medications for treating hyperlipidemias are very expensive, the plant studied here could be used as a very low cost support. However, for this, studies would be needed to ascertain the ideal doses that could be used without harming the organism. Some studies with this herb have shown no alterations in urea, creatinine, catalase, superoxide dismutase, glutathione peroxidase levels and no nephrotoxicity, but may be related with decreased iron absorption rats (Akdogan et al., 2003, 2004).

\section{ACKNOWLEDGEMENTS}

We are grateful to Prof. Dra. Ellen Guiguer Landgraf - Department of Pharmacology, Discipline of Homeopathy - UNIMAR, for her collaboration on the botanical identification. 


\section{RESUMO}

Os efeitos hipolipidêmicos de algumas plantas medicinais já foram demonstrados, mas muitas plantas que são comumente utilizadas pela população precisam ser estudadas. $\mathrm{O}$ objetivo deste trabalho foi verificar o efeito da Mentha piperita no perfil lipídico de ratos machos Wistar. Os animais foram divididos em grupo controle (CG) e quatro grupos experimentais: TG1 e TG2 receberam ração comercial normal, sendo que TG1 foi tratado com chá e TG2 com suco de $M$. piperita; TG3 e TG4 receberam ração enriquecida (com gordura hidrogenada e óleo de soja), sendo que TG3 foi tratado com chá e TG4 com suco. O tratamento foi feito por via intragástrica duas vezes ao dia durante 30 dias. Os animais de TG2 e TG4 tiveram diminuição significativa nos níveis de triacilglicerídeos e aumento nos níveis de HDLc. Houve aumento nos níveis de LDL-c em CG, mas nos demais grupos houve diminuição. TG1, TG2 e TG4 tiveram redução significativa no consumo alimentar e na porcentagem de ganho de peso. TG3 aumentou o consumo alimentar, mas não aumentou a porcentagem de ganho de peso.

\section{REFERENCES}

Akdogan, M., Gultekin, F., Yontem, M. (2004), Effect of Mentha piperita (Labiatae) and Mentha spicata (Labiatae) on iron absorption in rats. Toxicol Ind Health; 20(6-10), 119-22.

Akdogan, M., Kilinc, I., Oncu, M., Karaz, E., Delibas, N. (2003), Investigation of biochemical and histopathological effects of Mentha piperita L. and Mentha spicata L. on kidney tissue in rats. HumExp Toxicol; 22(4), 213-9.

Camacho, R. (1996), Ação da berinjela (Solanum melongena) sobre o nível de colesterol plasmático em coelhos. Thesis - Centro de Ciências Biológicas UEL - Londrina - PR - Brazil.

Choudhury, R. P., Kumar, A., Garg, A. N. (2006), Analysis of Indian mint (Mentha spicata) for essential, trace and toxic elements and its antioxidant behaviour. J Pharm Biomed Anal; 41(3), 825-832.

Cortez, L. E. R., Jacomosi, E., Cortez, D. A. G. (1999), Levantamento das plantas medicinais utilizadas na medicina popular de Umuarama, PR. Arq Cien.Saúde - UNIPAR; 3(2), 97- 104.

Del Castillo, M. L., Blanch, G. P., Herraiz, M. (2004), Natural variability of the enantiomeric composition of bioactive chiral terpenes in Mentha piperita. $J$ Chromatogr; 29, 1054(1-2), 87-93.
Doyama, J. T., Rodrigues, H. G., Novelli, E. L. B., Cereda, E., Vilegas, W. (2005), Chemical investigation and effects of the tea of Passiflora alata on biochemical parameters in rats. $J$. Ethnopharmacol; 96, 371-374.

Edris, A.E., Girgis, B. S., Fadel, H. M.( 2003), Recovery of volatile aroma components from aqueous waste streams using an activated carbon column. Food Chem; 82, 195-202.

Gogia, A., Agarwal, P.K. (2006), Metabolic syndrome. Indian J Med Sci; 60 (2), 72-81.

Ka, M. H., Choi, E. H., Chun, H. S., Lee, K. G. (2005), Antioxidative activity of volatile extracts isolated from Angelica tenuissimae roots, peppermint leaves, pine needles, and sweet flag leaves. J Agric Food Chem; 18; 53(10), 4124-9.

Kuo, K. L., Weng, M. S., Chiang, C. T., Tsai, Y. J., Lin-Shiau, S. Y., Lin, JK. (2005),Comparative studies on the hypolipidemic and growth suppressive effects of oolong, black, pu-erh, and green tea leaves in rat. J. Agric. Food Chem; 53(2), 480-9.

Lorenzo, C., Willian, K.; Hunt, K. J., Haffner, S.M. (2006), Trend in the prevalence of the metabolic syndrome and its impact on cardiovascular disease incidence: the San Antonio Heart Study. Diabetes Care; 29 (3), 625-30.

Manco, M., Calvani, M., Mingrone, G. (2004), Effects of dietary fatty acids on insulin sensitivity and secretion. Diabetes, Obesity and Metabolism; 6, 402413.

Lu, M., Battineli, L., Daniele, C., Melchione, C., Salvatore, G., Mazzanti, G. (2002), Muscle Relaxing Activity of Hyssopus officinalis Essential Oil on Isolated Intestinal Preparations. Plant. Med; 10(1055), 213-216.

Mimica-Dukic, N., Bozin, B., Sokovic, M., Mihajlovic, B., Matavulj, M. (2003), Antimicrobial and antioxidant activities of three Mentha species essential oils. Planta Med; 69(5), 413-9.

Romero-Jimenez, M., Campos-Sanchez, J., Analla, M., Munoz-Serrano, A., Alonso-Moraga, A. (2005), Genotoxicity and anti-genotoxicity of some traditional medicinal herbs. Mutat Res; 1 (1-2), 14755.

Sabarense, C. M., Mancini, J. F. (2003), Effect of the partially hydrogenated vegetable fato $n$ the incorporation of trans fatty acids in rat tissues. Rev Nutr; 16 (4), 399-407.

Samarth, R. M., Panwar, M., Kumar, M., Kumar, A. (2006), Radioprotective influence of Mentha piperita (Linn) against gamma irradiation in mice: Antioxidant and radical scavenging activity. Int $\mathbf{J}$ Radiat Biol.; 82 (5), 331-7.

Song, T., Lee, S.O. (2003), Soy protein with or without isoflavones, soy germ and soy germ extract, and daidzein lessen cholesterol levels in golden Syrian hamsters. Exp Biol Med; 228(9), 1063-1068. 
Vakkilainen, J., Makimattil, S., Seppala-Lindroos, A., Vehkayaara, S., Lahdenpera, S., Groop, P. H., Taskinen, M.R., Yki-Jarvinen, H. (2000), Endothelial Dysfunction in Men With Small LDL Particles. Clin Invest Reports; 102(7), 716-721.

Willa, A.H., Quiñones, M.J. (2003), Role of endothelial dysfunction in insulin resistence. Am J Cardiol; 92, 101-17.

Yki-Järvinen, H. (2003),Insulin resistance and endothelial dysfunction. Best Practice and Ressearch Clinical Endocrinology and Metabolism; 17, 411430.
Zou, Y., Lu, Y., Wei, D. (2005), Hypocholesterolemic effects of a flavonoid-rich extract of Hypericum perforatum L. in rats fed a cholesterol-rich diet. J Agric Food Chem; 7, 2462-6.

Received: December 08, 2006; Revised: May 28, 2007; Accepted: February 23, 2009. 